\title{
Poor Numbers: How We Are Misled by African Development Statistics and What to Do about It
}

Morten Jerven asks: What do we know about income and growth in sub-Saharan Africa? The answer is: much less than we like to think. The data are unreliable and potentially seriously misleading. The question is of great importance. Economic growth rates or per capita income estimates are commonly used in statements about development in Africa.

In my book Poor Numbers: How We Are Misled by African Development Statistics and What to Do about It, I have studied the measurement problems in African economies, and specifically analysed the methods and sources underlying the different GDP estimates that have been made since independence.

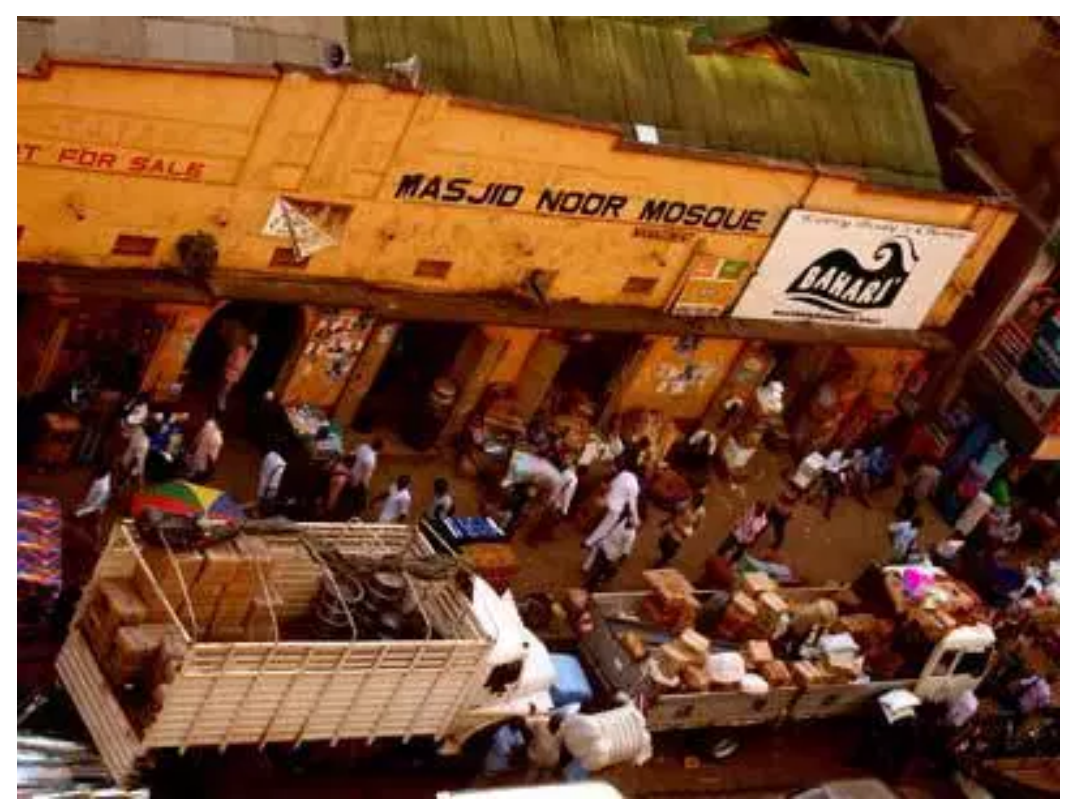

The measurement of African economies has long been an overlooked issue, but recently there have been some well publicised statistical events that warn data users that the African growth and income evidence does not tell us as much as we would like to think.

On 5 November 2010, Ghana Statistical Services announced that it was revising the GDP estimates upwards by over 60 percent, suggesting that in previous GDP estimates economic activities worth about US\$13 billion had been missed. After the revision a range of new activities were accounted for, and as a result Ghana was suddenly upgraded from a low-income country to a lower-middle-income country. In the autumn of 2011 Nigeria also announced a forthcoming upward revision of its GDP. This revision is not yet complete, but it has been suggested that the GDP revision in Nigeria will cause a similarly large jump in GDP. If GDP doubles in Nigeria following the revision it will mean that the GDP for the whole region increases by more than $15 \%$. The value of the increase amounts to as much as 40 economies roughly the size of Malawi's.

The revisions have caused confusion and disbelief in the development community. As I have explained in African Arguments, the cause for these large upward revisions is that the base year, the foundation of the system that generates GDP numbers had not been updated in Nigeria and Ghana for over two decades. As I report in my book, there are many countries that are currently in a similar position.

The conclusion is that any evaluation of whether Africa's rise is real or not must begin and end with a careful evaluation of the growth and income evidence. Without such analysis one runs the 
risk of reporting statistical fiction.

Thus, we may want to take the recent growth statistics from African economies with a pinch or two of salt, but is the recent rapid growth entirely statistical fiction? The answer is that some of it is, but that it is hard to tell exactly by how much - to paraphrase Donald Rumsfeld - there are many known unknowns in African growth statistics.

Quite a bit of the recent economic growth is not based on observed or recorded economic change, but is rather a result of what can be called statistical growth. Part of this growth is simply occurring by assumption - there is some growth in the formally recorded sector, and accountants adjust the GDP estimates to capture growth in the unrecorded sectors. This "informal economy" is by definition unrecorded, so the data added to the national accounts are very malleable. Nevertheless, this kind of growth by proxy is at least to some extent believable and defensible fiction.

What to do about it? For data users the policy implication is to question your evidence carefully. Although the time series data are readily downloadable from international databases, it is important to remember that these data are supplied from the national statistical offices, and to use the evidence correctly the same rules of source criticism of an historian applies. One needs to ask: under what conditions were these observations made? Is there other collaborating evidence that contradicts or confirms the observations?

The main burden lies with the disseminators and producers of statistics. The current system causes more confusion than enlightenment, yet governments, international organisations and independent analysts do need development statistics to track and monitor efforts at improving living conditions on the continent. One of the most urgent challenges in African economic development is thus to devise a strategy for improving statistical capacity.

The Millennium Development Goals put the measurement of development at the top of the agenda. The aim of the development community was summed up in 8 goals, 18 targets and 48 indicators. It is hard not to agree with the desirability of meeting these goals, yet it was somehow forgotten that the task of filling the information gap fell to the statistical offices in Africa and other poor economies around the world. The problem is that the map of statistical capacity on the African continent is very uneven today, and as a result any ranking of countries in Africa according to GDP and economic growth is going to be misleading. The first step towards a solution is to acknowledge the problem.

Morten Jerven is Assistant Professor at the Simon Fraser University, School for International Studies. His book Poor Numbers: how we are misled by African development statistics and what to do about it is published by Cornell University Press.

Morten Jerven will be present to launch the the book on Wednesday 22nd May 6 pm - 7 pm at the Waterstone's Economists' Bookshop at LSE Campus - Clare Market, London WC2A 2AB

May 6th, 2013 | Development | 2 Comments 
